\title{
Comparação de Materiais Didáticos Impressos de Microbiologia de Dois Cursos Brasileiros Semipresenciais de Licenciatura em Ciências Biológicas
}

\author{
Ludmila Silva Brighenti $^{* 1}$, Graziela Jardim Pacheco², Maria Gouveia Matos³
}

\begin{abstract}
1 Doutora em Ecologia, Conservação e Manejo da Vida Silvestre pela Universidade Federal de Minas Gerais. Pós-doutoranda do LIMNEA/Biologia Geral/UFMG. Endereço: Av. Antônio Carlos, 6627, Pampulha - Belo Horizonte - MG - Brasil. ludmilasb@gmail.com

2 Doutora em Bioquímica pela UFRJ. Tecnologista em Saúde Pública da Fundação Oswaldo Cruz Farmanguinhos/ Fiocruz - Rua Sizenando Nabuco 100 - Manguinhos, Rio de Janeiro - RJ - Brasil. grazielapacheco@far.fiocruz.br

3 Doutoranda em Ciências Humanas e Educação pela PUC/Rio. Professora do Colégio de Aplicação da Universidade Federal do Rio de Janeiro - CAp/UFRJ-Rua J.J. Seabra s/n. Jardim Botânico - Rio de Janeiro RJ - Brasil. mariamatos@yahoo.com.br
\end{abstract}

\section{Resumo}

Materiais didáticos impressos para Educação a Distância (EaD) necessitam de características especiais que promovam a autonomia do aluno, incentivem-no a buscar mais informações e agucem seu gosto pelo conhecimento. Nesse contexto, este trabalho objetivou analisar e comparar a arquitetura da informação e as atividades de materiais didáticos impressos utilizados na disciplina Microbiologia dos cursos semipresenciais de Licenciatura em Ciências Biológicas do Consórcio Centro de Educação a Distância do Estado do Rio de Janeiro (Cederj) e da Universidade Federal de Minas Gerais (UFMG). Foi observada, em ambos os materiais, conectividade adequada, propiciando a dinâmica ativa de estudo. No entanto, o fascículo do Cederj apresentou menor linearidade, sendo rico em caixas de informações periféricas que possibilitam diferentes rotas de leitura. Em ambos os materiais foram observadas atividades predominantemente de caráter formativo ao longo do texto e ao final das aulas, permitindo a gradativa construção do conhecimento mediante a verificação constante da aprendizagem.

Palavras-chave: Material didático impresso; Arquitetura da informação; Feedback; Avaliação. 


\title{
Comparison of Printed Educational Material for Microbiology in Blended Undergraduate Courses on Biological Sciences
}

\begin{abstract}
Printed courseware for distance education requires special features that promote student autonomy, encourage the search for more information and excite their interest for the course and for the studies. In this context, this study aimed to analyze and compare the information architecture and activities of printed educational materials used in the discipline of microbiology in the blended undergraduate courses in Biological Sciences from Consórcio Centro de Educação Superior a Distância do Estado do Rio de Janeiro (Cederj) and Universidade Federal de Minas Gerais (UFMG). Both materials tested had adequate connectivity, providing an active dynamic of the study. However, the Cederj material showed lower linearity, being rich in peripheral information boxes that allow different readings routes. In both materials, the presences of activities throughout the text and at the end of each chapter were observed. These activities were predominantly formative, which allow the gradual construction of knowledge by constantly checking the self-learning.
\end{abstract}

Keywords: Printed courseware; Information architecture; Feedback; Evaluation. 


\section{Introdução}

A EaD, em seu processo histórico de evolução, sempre utilizou as inovações tecnológicas como forma de comunicação entre o professor e o aluno (Nunes, 2009). Atualmente, com o advento das tecnologias da informação e comunicação (TIC), a EaD atinge alta representatividade e se mostra uma importante alternativa para a democratização do acesso ao ensino (Campos et al., 2007).

Apesar da diversidade tecnológica disponível para auxiliar no processo de aprendizagem, a gestão de programas a distância apresenta diversos desafios, muitos deles bem diferentes daqueles apresentados nos cursos presenciais (Zuin, 2006). Na EaD, o aluno não está fisicamente presente em todos os momentos da relação dialógica, de tal modo que o material didático é o instrumento utilizado para esse diálogo, devendo ser pensado e concebido no interior de um projeto pedagógico mais amplo (Cardoso et al., 2012).

No presente trabalho analisamos a presença de características consideradas desejáveis em materiais didáticos impressos (MDI) para EaD, já que é notória sua importância para o desenvolvimento da autonomia do aluno. Foram analisados os MDI da disciplina Microbiologia oferecida nos cursos de Licenciatura em Ciências Biológicas do Cederj e da UFMG. Trata-se de instituições de ensino superior públicas; o Cederj é um consórcio formado por seis universidades públicas sediadas no Estado do Rio de Janeiro. Ambas fazem parte do sistema federal da Universidade Aberta do Brasil e estão diretamente envolvidas em ações voltadas para a interiorização do ensino superior público, gratuito e de qualidade, por meio de cursos superiores a distância.

\subsection{Características desejáveis em materiais didáticos impressos para EaD}

O MDI é de importância conhecida para o processo de ensino-aprendizagem, seja ele presencial ou a distância. Segundo Barreto (2006), o MDI traz grandes vantagens, tais como a flexibilidade de horário e local de estudo, além de proporcionar ao leitor a possibilidade de se aprofundar em diferentes níveis e seguir seu próprio ritmo de leitura. Apesar de as TIC permitirem a diversificação de mídias utilizadas em EaD, os materiais didáticos impressos ou livros eletrônicos representam o principal recurso educacional em $25 \%$ dos cursos a distância autorizados ou reconhecidos pelo 
MEC no Brasil (ABED, 2012). Esses dados reforçam a necessidade de pesquisar e refletir sobre a qualidade dos MDI.

$\mathrm{Na} E a \mathrm{D}$, os MDI deverão apresentar características peculiares essenciais para que atinjam seus objetivos. Schons (2009) elenca algumas dessas características, entre elas a presença dos princípios da autonomia e do autodidatismo, os quais se fazem presentes mediante a transmissão não só de conteúdos, mas também de técnicas, hábitos, valores e atitudes. Por exercer a função de mediação pedagógica, a relevância do material didático na EaD deve superar a do ensino presencial e constitui aspecto de fundamental importância nessa modalidade de educação. Para alcançar a meta de aprendizagem, o material didático deverá ser motivador para a autoaprendizagem e, de alguma forma, promover a busca da interação entre os alunos e o professor, ajudando a minimizar a distância relacional.

Para elaborar um material didático que atenda e alcance o seu objetivo, o Ministério da Educação, por meio dos Referenciais de Qualidade para a Educação Superior a Distância (Brasil, 2007), enumera alguns princípios fundamentais a serem atendidos. Dentre eles se destacam o acesso aos conhecimentos e informações que possibilitem a organização do conhecimento prévio trazido pelo estudante, a compreensão crítica da situação apresentada e a sua intervenção no contexto social, político e cultural. É desejável ainda que o material didático apresente referências que instiguem maior exploração dos assuntos apresentados e permitam a integração entre as unidades de aprendizagem, levando o estudante à reflexão sobre sua própria importância no processo.

É importante estar atento às características dos elementos instrucionais que compõem os MDI de modo que atuem de forma significativa no processo de aprendizagem a distância. Dentre estes elementos podem ser destacados a arquitetura da informação, o Feedback e a avaliação por meio de atividades propostas ao longo do MDI, os quais serão discutidos a seguir.

\subsection{Arquitetura da informação}

Arquitetura da informação pode ser definida como "a organização estrutural da informação a ser oferecida de acordo com o meio pelo qual essa informação é veiculada e o propósito a que se presta" (Abreu-Fialho; Barreto, 2008, p. 3). O termo 
arquiteto da informação foi criado por Richard Saul Wurman na década de 1960, ao perceber que a grande quantidade de dados sendo produzidos num curto espaço de tempo dificultaria imensamente a tradução dos mesmos em informação (Agner \& Silva, 2003).

Aplicando o conceito ao MDI, podemos dizer que a arquitetura da informação é o que vai permitir ou não (dependendo da qualidade da aplicação de seus princípios) a leitura não linear e diferenciada de acordo com o leitor. Mais especificamente, no caso do MDI para a EaD, a arquitetura da informação deve organizar o conteúdo de forma que esteja centrado no aluno e que incentive sua participação na aula, por exemplo, com um texto permeado por atividades (Ramos et al., 2007).

Para isso, são utilizados diferentes recursos que permitem ao aluno percorrer diversas rotas de estudo a partir de desdobramentos do conteúdo que podem estruturar a informação de acordo com variados propósitos educativos. Segundo Ramos et al. (2007), os recursos (informações periféricas) da arquitetura da informação podem ser divididos de acordo com a sua dinâmica informativa entre aqueles que propiciam o movimento para dentro da aula e os que propiciam o movimento para fora da aula. Alguns exemplos desses recursos são: a caixa de ênfase (alerta sobre informações importantes), de explicação expandida (contextualiza conceitos, apresenta situações), de dicionário (apresenta definições), de curiosidade (integração da informação com conceitos extra-aula) e de conexões com outras mídias (Figura 1).

Além disso, a arquitetura da informação envolve a presença de organizadores prévios (lista de conteúdo, mapa conceitual, diagramas), estruturação do texto (numeração, destaques, ícones) e índices de acesso, de maneira que permita a localização fácil da informação, o entendimento do contexto da aula e dos objetivos que devem ser alcançados (Preti, 2010).

\subsection{Feedback e avaliação}

Na EaD, a avaliação é um dos instrumentos importantes para o sucesso do curso, visto que é por meio dela que se obtém o Feedback de todo o processo. Por meio da avaliação é possível verificar em que medida os objetivos estão sendo 
alcançados, para ajudar o aluno a avançar na construção do seu saber, bem como obter Feedback do trabalho docente e discente (Silva, 1998).

De acordo com a função a que se aplicam, as atividades disponibilizadas em um MDI podem ser classificadas, segundo Bloom e colaboradores (1971), como diagnósticas, formativas e somativas. Assim, atividades com função diagnóstica buscam detectar as condições em que os alunos se encontram ao iniciar um curso, uma unidade, um tópico ou um tema de estudo. Procuram verificar a presença ou ausência de habilidades, interesses e necessidades de cada aluno, além de auxiliar o professor na identificação de aspectos do conteúdo que precisam ser reforçados para seguir adiante (Silva, 1998).

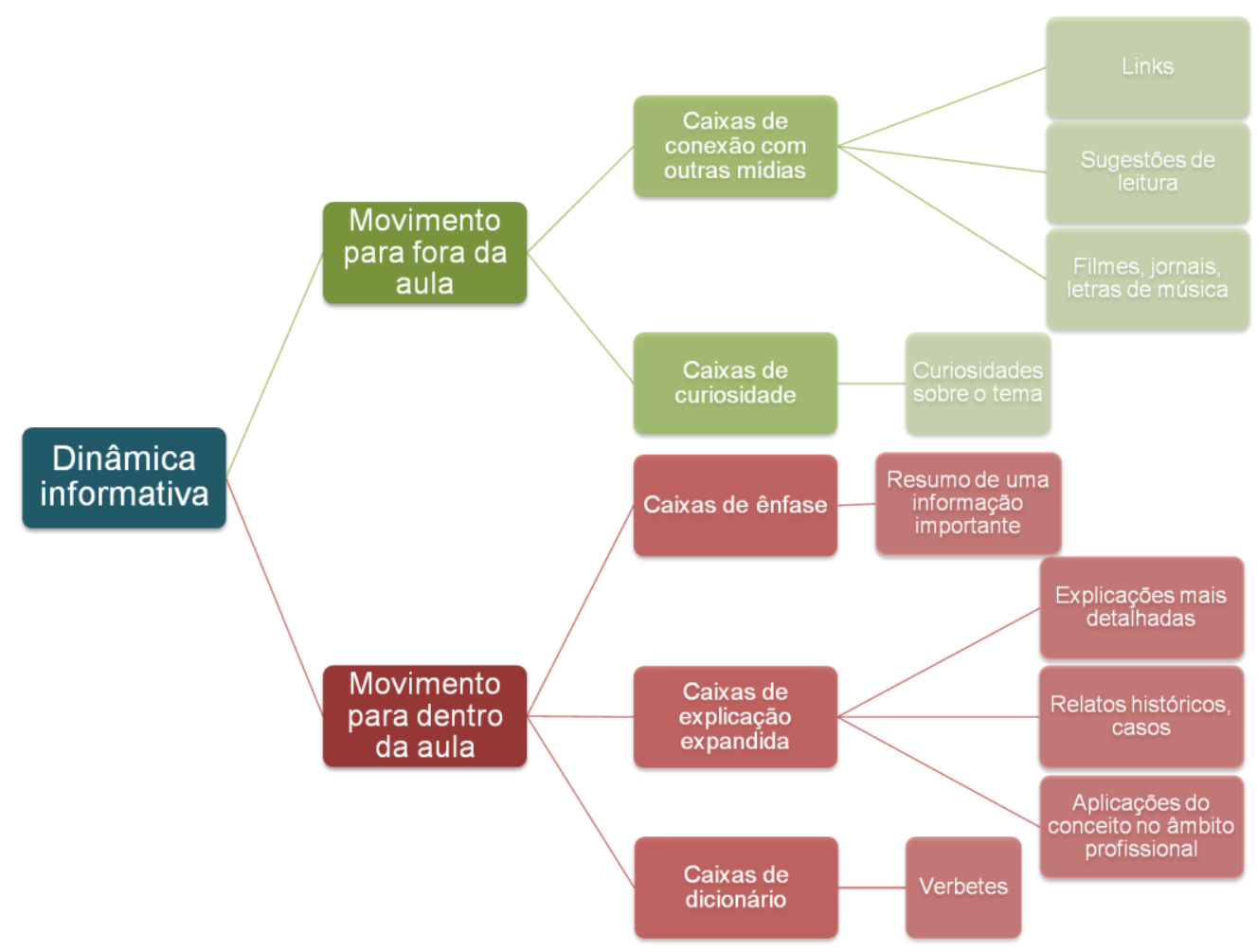

Figura 1. Dinâmica informativa de MDI para EaD.

Fonte: Adaptado de Ramos et al. (2007).

Atividades com função formativa procuram detectar falhas ou insucessos no decorrer da aprendizagem, indicando como os alunos estão se modificando em direção aos objetivos pretendidos. Em outras palavras, a avaliação formativa fornece um Feedback aos alunos acerca da sua progressão para que possam alterar a maneira 
como abordam o curso, se for necessário. Além disso, pode contribuir para 0 aperfeiçoamento da prática docente, adequando os procedimentos de ensino às necessidades dos alunos detectadas durante o processo de aprendizagem (Silva, 1998).

A função somativa permite verificar ao final de um processo (tema, tópico, unidade, módulo) se os comportamentos desejados foram alcançados. Permite ainda classificar resultados quantitativos e qualitativos obtidos pelos alunos tendo por base de comparação os níveis de aproveitamento preestabelecidos (Silva, 1998).

Uma vez presentes no MDI, avaliações diagnósticas, formativas e somativas poderão permitir o aumento da motivação, proporcionado pelo maior controle do aluno sobre sua aprendizagem. Isso se torna possível devido ao fornecimento de meios que permitam avaliar sua progressão e reconhecer de forma imediata os seus avanços e necessidades de aprofundamento.

Nesse contexto, levando em consideração as características desejáveis em um MDI apresentadas, a investigação da arquitetura da informação e das atividades presentes nos MDI poderão nos ajudar a entender parcialmente de que forma o Feedback está sendo desenvolvido.

\section{Metodologia}

Neste trabalho foram analisados MDI da disciplina Microbiologia, presente nos cursos semipresenciais de Licenciatura Plena em Ciências Biológicas oferecidos pelo Cederj e pela UFMG.

O MDI utilizado no curso oferecido pela UFMG é um volume único com quatro aulas e 6 anexos que incluem atividades práticas. As aulas podem se constituir em apresentação, reflexões e indagações teóricas, em experimentos ou em orientações para atividades a serem realizadas pelos estudantes (Correa Jr., 2006).

O MDI utilizado no curso oferecido pelo Cederj subdivide-se em dois volumes, totalizando 18 aulas. Dentre elas, sendo 13 teóricas e 5 práticas; o segundo grupo é desenvolvido presencialmente nos polos (Liberto et al., 2006a, b). 


\subsection{Critérios de análise}

\subsubsection{Arquitetura da informação}

O grau de linearidade e de conectividade foi medido pelo número de informações periféricas em cada aula. Essas informações foram classificadas de acordo com o seu conteúdo e com a sua dinâmica informativa, segundo Ramos et al. (2007) em:

Direcionam para dentro da aula:

1. Caixas de ênfase

2. Caixa de explicação expandida

3. Caixa de dicionário

Direcionam para fora da aula:

4. Caixa de informação avulsa ou de curiosidade

5. Caixa de conexão com outras mídias

A estruturação do texto foi analisada com base na ausência/presença de organizadores prévios (lista, mapa conceitual, diagramas) e de numerações, destaques e ícones (Preti, 2010).

\subsubsection{Feedback e avaliação}

Para analisar qualitativa e quantitativamente as atividades presentes nos MDI dos cursos investigados, foram consideradas a frequência com a qual as atividades são disponibilizadas ao longo dos materiais, sua localização no texto e a finalidade com a qual foram elaboradas, levando em consideração aspectos de autoavaliação, técnicos, a capacidade de integração dos conceitos com a resolução de problemas, bem como a integração com outras disciplinas. Foi avaliada também a linguagem utilizada na redação de tais atividades, além da presença de resoluções comentadas.

Seguindo as classificações de atividades de acordo com as funções a que se aplicam, os MDI foram analisados quanto à presença de atividades do tipo diagnóstica, formativa ou somativa (Bloom et al., 1971). Sua escolha foi baseada na contribuição de cada uma dessas atividades para o processo de aprendizagem, incluindo a deteç̧ão 
da condição em que os alunos se encontram ao iniciar a aula, a identificação de falhas ou insucessos no decorrer da aprendizagem e a verificação, ao final da aula, se os objetivos propostos foram alcançados.

\section{Resultados e discussão}

\subsection{Arquitetura da informação}

No MDI da disciplina oferecida pelo curso do Cederj, cada aula é subdividida em tópicos como introdução, diferentes seções com desenvolvimento do conteúdo, conclusão e resumo. Não é feito uso de organizadores prévios, como diagramas, mapas conceituais ou listas de conteúdo. Contudo, no início de cada aula são apresentadas metas, objetivos e os pré-requisitos da aula, o que dá ao aluno a noção do conteúdo a ser abordado. A presença desses organizadores prévios facilita a aprendizagem, pois serve como "ponte entre o que o aprendiz já sabe e o que ele deve saber, a fim de que o material possa ser aprendido de forma significativa" (Vaz \& Raposo, 2014, s. p.). A versão impressa do MDI do Cederj, disponibilizado no polo para o aluno, apresenta um sumário geral com a lista de tópicos do fascículo, porém, na versão disponível em pdf na plataforma do curso esse índice não é disponibilizado.

No MDI de Microbiologia da UFMG, um capítulo de introdução é apresentado, o qual traz a organização do fascículo, apresenta os conteúdos a serem abordados, a ordenação das atividades e a formatação. Além da introdução, há também um sumário geral com as listas de tópicos dos capítulos. Esses chamados índice de acesso, assim como a conectividade, são de grande importância para a autonomia do aluno, pois permitem que o leitor selecione as partes do seu interesse naquele momento. Além disso, "orientam o leitor sobre o percurso do texto, sua estrutura e aspectos centrais ou importantes a serem lembrados ou assimilados" (Preti, 2010, p. 77). As aulas, assim como as do MDI do Cederj, são divididas em tópicos e no tópico inicial de cada aula são apresentados os conteúdos que serão abordados.

No que diz respeito à presença de elementos periféricos, mais de $40 \%$ das aulas do MDI do Cederj apresenta elementos periféricos. Levando em conta os pressupostos da Teoria da Flexibilidade Cognitiva, que diz que o aluno bem-sucedido é aquele capaz de escolher conhecimentos para diversas situações (Araújo et al., 2008), esses vários 
desdobramentos que orientam e favorecem a sua autonomia são muito importantes, pois permitirão ao aluno seguir diferentes caminhos em busca do conhecimento.

Ao contrário do fascículo de Microbiologia do Cederj, o texto do MDI da UFMG não apresenta caixas de informações periféricas. As informações e as conexões com outras mídias são feitas ao longo do corpo principal do texto ou por meio dos anexos (que contêm informações do tipo de caixas de explicação expandida e de curiosidades, por exemplo).

De acordo com Antunes (2011), os elementos periféricos podem aumentar a fluidez do texto e atender a alunos de diferentes perfis. Um leitor mais seguro dos conceitos, por exemplo, pode ignorar as caixas e um leitor com mais dificuldade pode fazer pausas e ler explicações adicionais que irão ajudá-lo na assimilação do conteúdo. Desse modo, uma alternativa à linearidade do texto no MDI da UFMG seria utilizar o mesmo conteúdo já presente no fascículo, porém mudando a maneira de organizar as informações. Na aula 2, página 33, por exemplo, poderia ser criada uma caixa de curiosidade com as informações do segundo parágrafo (Figura 2). Essa modificação fornece ao aluno a opção de ler aquela informação em diferentes momentos, aumentando sua autonomia e aguçando a sua curiosidade.

Em relação à dinâmica informativa no MDI do curso oferecido pela UFMG, em $90 \%$ dos casos o aluno é estimulado a buscar informações fora da aula por meio de indicações de vídeos e textos na página da disciplina no ambiente virtual e, principalmente, por meio da indicação da leitura dos anexos do fascículo. Silva (2010) encontrou o mesmo padrão de ênfase no movimento para fora da aula no MDI de Citologia Animal e Vegetal da UFMG. Segundo a autora, essa conectividade que o texto estabelece com outros são como "portas se abrindo, pois são informações que se somam com o conteúdo central" (Silva, 2010, p. 21).

O inverso foi observado no MDI do Cederj. Neste caso, os recursos periféricos promovem o movimento do aluno, em sua maioria, para dentro da aula (74\%). A maior porcentagem de recursos que propiciam o movimento para dentro da aula foi fortemente influenciada pela grande quantidade de caixas de dicionário, as quais representam $62 \%$ das informações periféricas do MDI, seguidas por $18 \%$ de caixas de curiosidade e $9 \%$ de caixas de explicação expandida. 
As caixas de dicionário do MDI do Cederj aparecem sempre na parte lateral das páginas; algumas caixas aparecem cortando o texto principal. As caixas que se encontram ao longo do texto principal chamam a atenção do aluno e devem conter conteúdos que se deseja enfatizar. Nas caixas laterais devem ser inseridas informações que não são essenciais para a leitura do texto principal, deixando para o leitor a escolha de ler ou não aquele conteúdo em determinado momento (Ramos et al., 2007; Preti, 2010; Antunes, 2011).

\section{INTRODUÇÃO}

$(A)$

Vírus são partículas de material nucléico, complexados ou não a proteínas, que necessitam obrigatoriamente de uma célula hospedeira para a sua multiplicação. A morfologia e tamanho dos vírus é variada. $\mathrm{O}$ seu tamanho varia entre 20 e $14.000 \mathrm{~nm}$ e formas arredondadas, alongadas e mistas são observadas.

A palavra vírus é originária do latim e significa veneno. $O$ primeiro vírus purificado e caracterizado foi o vírus do mosaico do tabaco em 1935 por Wendell M. Stanley, no departamento de fitopatologia da Universidade de Princeton, nos Estados Unidos. Os achados de Stanley causaram um grande impacto na ciência, auxiliando na compreensão do papel do material nuclear na transferência de características hereditárias, sendo os trabalhos agraciados com o prêmio Nobel de química em 1946.

\section{INTRODUÇÃO}

(B) Vírus são partículas de material nucléico, complexados ou não a proteínas, que necessitam obrigatoriamente de uma célula hospedeira para a sua multiplicação. A morfologia e tamanho dos vírus é variada. $\mathrm{O}$ seu tamanho varia entre 20 e $14.000 \mathrm{~nm}$ e formas arredondadas, alongadas e mistas são observadas.

A palavra vírus é originária do latim e significa veneno. O primeiro vírus purificado e caracterizado foi o vírus do mosaico do tabaco em 1935 por Wendell M. Stanley, no departamento de fitopatologia da Universidade de Princeton, nos Estados Unidos. Os achados de Stanley causaram um grande impacto na ciência, auxiliando na compreensão do papel do material nuclear na transferência de características hereditárias, sendo os trabalhos agraciados com o prêmio Nobel de química em 1946.

Figura 2. Texto original do fascículo de microbiologia da UFMG (A) e sugestão de desdobramento do referido texto principal (B).

Fonte: Corrêa Jr. (2006, p. 33). 
Além das caixas de informações periféricas, as aulas do MDI do Cederj trazem ao longo do corpo principal do texto muitas chamadas para aulas de outras disciplinas e links de conexão com outras mídias. Essas sugestões de outras bibliografias indicam a conectividade do MDI, a qual é muito importante para que o aluno faça uma leitura de forma ativa, criando sua própria rota de estudo (Silva Filho, 2010).

Segundo Ramos et al. (2007), o quanto um aluno irá aproveitar das informações disponíveis em uma aula depende do tempo disponível e do interesse do aluno pelo conteúdo. Portanto, arquitetura da informação eficiente é aquela que oferece todos os elementos necessários para atender alunos de diversos perfis de disponibilidade de tempo e graus de interesse. Sendo assim, o ideal é que haja equilíbrio entre as informações que irão permitir ao aluno menos familiarizado com o assunto um aprofundamento do conteúdo da aula (caixas que propiciam movimento para dentro da aula) e, ao mesmo tempo, permitir que o aluno mais interessado possa ampliar seus conhecimentos sobre o assunto (caixas que propiciam o movimento para fora da aula).

Os MDI do Cederj e da UFMG poderiam ser também enriquecidos com o uso de ícones, que oferecem ao estudante pistas visuais para que ele identifique, de imediato, aquilo que determinado parágrafo trata (Preti, 2010). O MDI do Cederj apresenta ícones para indicar as caixas de atividades e para dar ênfase a algumas caixas - utiliza uma exclamação (Figura 3). Porém as caixas com exclamação são encontradas remetendo a diferentes tipos de informações, tais como curiosidade ou conexão com outras mídias, o que pode confundir o leitor em relação ao tipo de informação que a caixa possui. O ideal seria que os ícones fossem específicos para o tipo de caixa, para que o aluno possa rapidamente fazer a associação entre o ícone e o tipo de informação que vai encontrar. 
(A)

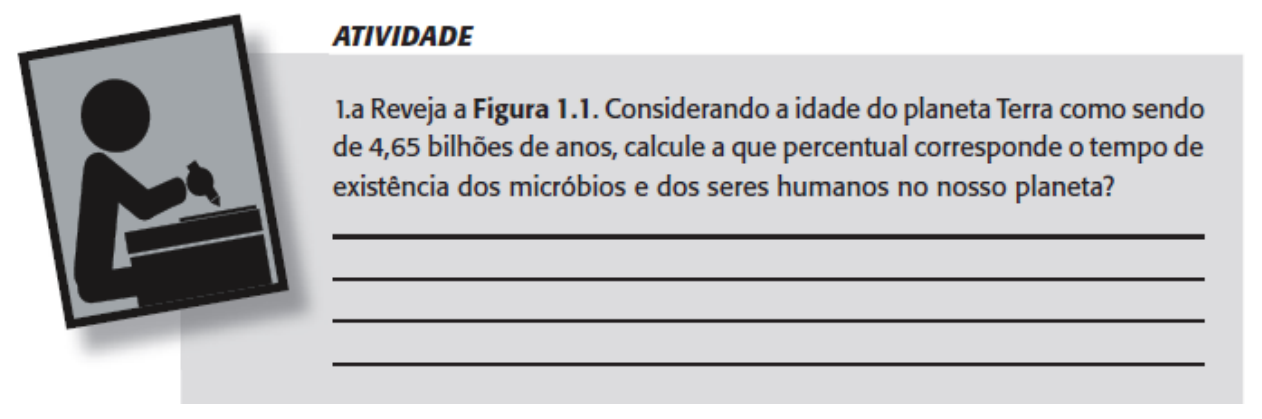

(B)

Você poderá ver mais detalhes sobre o espectro eletromagnético visitando o site (http://leobenez.tripod.com/muitas-luzes.html).

Figura 3. Exemplos de ícones utilizados em caixas de atividades $(A)$ e de ênfase, curiosidade ou conexão com outras mídias (B).

Fonte: Liberto et al. (2006a, pp. 12, 14).

\subsection{Feedback e avaliação}

No que diz respeito às atividades apresentadas a fim de promover o Feedback e a avaliação do aluno, a maior parte das aulas do MDI do Cederj as apresenta distribuídas ao longo do texto, seguidas de uma resposta comentada e ao final de cada aula, procurando abordar os principais conceitos tratados nela. No MDI da disciplina oferecida pela UFMG, por sua vez, todas as aulas iniciam com um procedimento experimental a ser realizado pelo aluno, o qual remete a uma série de questões e conceitos que deverão ser respondidos e compreendidos pelo aluno. Após a descrição do experimento, o aluno é convidado a ler o texto subsequente, onde os fundamentos teóricos da disciplina são abordados. Ao fim da leitura, o aluno deve redigir um relatório da atividade (conforme modelo exposto em um dos anexos do MDI) e responder a uma série de questões de reforço.

A Tabela 1 apresenta o perfil geral das atividades propostas ao longo das aulas de ambos os MDI analisados, bem como suas principais características.

As tabelas devem apresentar informações nas quais o dado numérico se destaca como informação relevante. $O$ título deve ficar sempre acima (Tabela 1). 
Tabela 1: Principais características das atividades propostas ao longo das aulas de Microbiologia dos MDI do curso da UFMG e do Cederj

\begin{tabular}{lcccc}
\hline & $\begin{array}{c}\text { Total de } \\
\text { atividades }\end{array}$ & $\begin{array}{c}\text { Presença de } \\
\text { respostas } \\
\text { comentadas }\end{array}$ & $\begin{array}{c}\text { Integração com } \\
\text { outras } \\
\text { disciplinas }\end{array}$ & $\begin{array}{c}\text { Integração de } \\
\text { conceitos com } \\
\text { situações } \\
\text { cotidianas }\end{array}$ \\
\hline UFMG & 33 & Não & Não & Poucas vezes \\
CEDERJ & 63 & $\begin{array}{c}\text { Sim, ao final de } \\
\text { cada atividade }\end{array}$ & Frequentemente & Frequentemente \\
\hline
\end{tabular}

Em ambos os MDI foi observado grande número de atividades, fundamentais para a construção do conhecimento do aluno, sua verificação da aprendizagem, motivação e autonomia para prosseguir em seus estudos. Embora a quantidade total de atividades presente no MDI do Cederj tenha sido bastante superior à do curso oferecido pela UFMG, essa diferença pode estar relacionada à maior quantidade de aulas presentes no material do Cederj.

Outras diferenças marcantes observadas nos MDI analisados dizem respeito à presença de respostas comentadas e à integração de conceitos com outras disciplinas do curso e com situações cotidianas, as quais estão mais presentes no MDI do Cederj. Enquanto neste MDI todas as atividades apresentam respostas comentadas, elas são inexistentes no MDI do curso oferecido pela UFMG. A ausência de um gabarito ou de uma resolução comentada traz consequências diretas ao desenvolvimento da autonomia do aluno, uma vez que ele se torna dependente do tutor no que diz respeito à verificação de sua aprendizagem.

De acordo com Silva (1998), o ato de avaliar consiste em verificar se os objetivos propostos estão sendo alcançados. Do mesmo modo, um dos mecanismos utilizados para fornecer o Feedback aos alunos inclui a incorporação de exercícios de autoavaliação nos materiais impressos, com exemplos de respostas logo a seguir à pergunta ou no final da unidade. Outra estratégia seria a inclusão de referências a outros textos e livros que discutam as questões apresentadas, com possíveis exemplos 
de resposta à atividade (INED, 2003). Dessa forma, a ausência de resoluções comentadas dificulta consideravelmente a verificação da progressão pelo próprio aluno.

Em relação à disposição das atividades ao longo das aulas, em ambos os MDI é observada a predominância de atividades ao longo do texto (70 a 76\% das atividades) em comparação com aquelas presentes ao final das aulas. Ribeiro \& Provenzano (1997) ressaltam que as atividades ao longo e ao final dos textos das aulas são comuns em MDI para EaD. Sua localização costuma estar relacionada com as funções a que se destinam, tais como levar o aluno a relacionar a teoria e a prática por meio de questões orientadoras ou promover a autoavaliação e identificação dos avanços na aprendizagem ao final de um capítulo. Assim, a predominância de atividades dispostas ao longo do texto permite que o aluno verifique gradativamente sua aprendizagem antes de prosseguir em sua leitura, o que parece bastante adequado para o processo de ensino-aprendizagem.

No que diz respeito à classificação das atividades de acordo com a nomenclatura proposta por Bloom et al (1971), foi observado que a ampla maioria das atividades presentes em ambos os MDI apresentam a função formativa. Essa predominância, sempre dispostas ao longo do texto, segue uma tendência observada em materiais didáticos para EaD. De acordo com Dutra et al (2008), a avaliação formativa ainda é pouco aplicada. Em termos de EaD, no entanto, o processo de avaliação formativa tem sido bastante valorizado principalmente por permitir o constante Feedback aos alunos e por permitir que professores e alunos regulem o processo de ensino-aprendizagem a distância.

A Figura 4 apresenta o percentual de atividades presentes nos MDI dos cursos oferecidos pelo Cederj e pela UFMG em função da sua classificação. Nota-se que cerca de $70 \%$ das atividades apresentam caráter formativo e 24 a 30\% das atividades são somativas. Apenas o material didático do Cederj apresenta atividades com função diagnóstica, as quais representam $4,76 \%$ do total de atividades. 


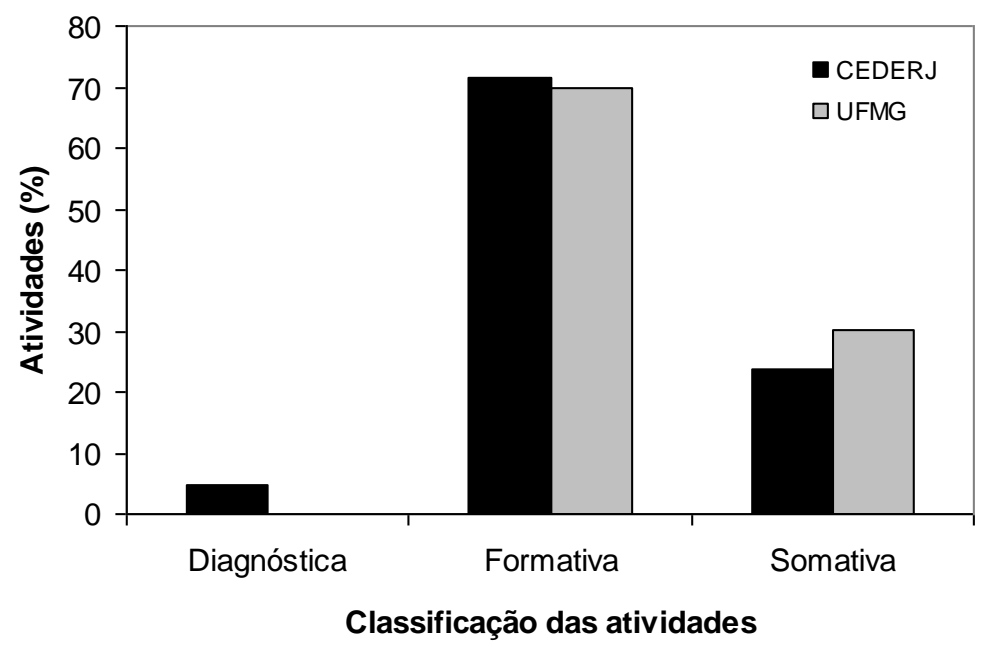

Figura 4. Classificação das atividades presentes nos MDI da disciplina oferecida pelo Cederj e pela UFMG

As atividades diagnósticas apresentadas no MDI do Cederj trazem questões que envolvem tanto o resgate de conceitos trabalhados no Ensino Médio quanto àqueles referentes a outras disciplinas do curso. Nesse tipo de atividade fica evidente a intenção do autor de verificar a presença (ou ausência) prévia de habilidades específicas, indicando ao aluno eventuais aspectos do conteúdo que precisam ser aperfeiçoados antes de iniciar seus estudos em determinada aula.

Em relação às atividades formativas presentes no MDI do Cederj e da UFMG, é possível observar a intenção constante dos autores de fornecer ao aluno a percepção de seu progresso em relação àquilo que está sendo proposto ao longo da aula. No caso do MDI do Cederj, muitas vezes o enunciado dessas atividades apresenta situações práticas de resolução de problemas e/ou integração com conhecimentos de outras disciplinas, como Bioquímica, Biologia Celular e a Ecologia. No MDI da UFMG foi observado que os enunciados das atividades se apresentam de forma mais direta, em sua maioria sem fazer referência à integração com conceitos trabalhados em outras disciplinas ou com situações do cotidiano. A Figura 5 apresenta exemplos de atividades formativas presentes no MDI do Cederj e da UFMG. A atividade do MDI do Cederj descrita nessa figura busca integrar conceitos de Bioquímica e Microbiologia. Já a 
atividade do MDI da UFMG exemplificada é encontrada logo após a descrição dos procedimentos experimentais de uma atividade prática envolvendo bacteriófagos.

(A)

\begin{abstract}
1. Imagine duas amostras bacterianas $A$ e $B$, cada uma delas inoculada em dois tubos de ensaio contendo, além dos ingredientes comuns, glicose e um indicador de pH. Após a inoculação, um dos tubos de cada cultura é adicionado de uma camada de óleo mineral esterilizado. Vinte e quatro horas após, você observa que as células da amostra $A$ desenvolveram-se apenas no tubo sem óleo, enquanto as células da amostra $B$ desenvolveram-se nos dois tubos. Na cultura da amostra $A$, após o crescimento, o pH do meio não ficou alterado, enquanto para a amostra $B$ o pH ficou acidificado em ambos os tubos. Pode-se notar, ainda, que o crescimento populacional da amostra $A$ em relação à amostra $B$, no tubo sem óleo, foi muito mais acentuado. Diante dessas informações, interprete o metabolismo das amostras $A$ e $B$ quanto ao processo de respiração e fermentação e ao rendimento energético do processo, em função do crescimento populacional e das amostras microbianas examinadas.
\end{abstract}

Fonte: Liberto et al. (2006a, p. 117).

(B)

Observação dos resultados

Todos os tubos apresentam o mesmo aspecto? Por que não?

Todas as placas apresentam o mesmo número de taches?

Você é capaz de calcular quantos bacteriófagos existiam na solução inicial?

O que é título?

Nas menores diluições você observou o crescimento de pequenas colônias? O que são estas colônias?

Fonte: Corrêa Jr. (2006, p. 34).

Figura 5: Exemplos de atividades formativas presentes no MDI do Cederj ( $A$ ) e da UFMG (B).

Logo após a atividade mostrada na Figura 5A, os autores apresentam uma resposta comentada:

A amostra $A$ só cresce na presença de oxigênio, logo é um tipo bacteriano aeróbico estrito. A amostra B cresce nos dois tubos, acidificando o meio. Isso mostra tratar-se de um micróbio fermentativo, facultativo quanto à presença de oxigênio. O crescimento mais acentuado na amostra que faz respiração deve-se ao rendimento energético na respiração (fosforilação oxidativa) ser maior do que na fermentação, como você aprendeu na Aula 16 sobre metabolismo de carboidratos II, da disciplina Bioquímica II (Liberto et al., 2006a, p. 118). 
Respostas comentadas como a transcrita foram encontradas ao longo de todas as atividades propostas do MDI do Cederj, utilizando uma linguagem clara, objetiva e encorajando o aluno a uma abordagem mais profunda da aprendizagem. Além de permitir ao aluno uma verificação imediata de seu processo de aprendizagem, a resposta comentada indica fontes de consulta para eventuais dúvidas referentes à realização da atividade e faz referência direta ao MDI de outra disciplina do curso, tornando clara a relação existente entre as duas áreas de estudo.

Diferentemente das discutidas anteriormente, as atividades somativas presentes ao final de cada aula dos MDI do Cederj e da UFMG apresentam questionamentos mais diretos e, na maior parte das vezes, mais abrangentes que aqueles dispostos ao longo das aulas (Figura 6). No entanto, apenas o MDI do Cederj disponibiliza respostas comentadas com certo grau de detalhamento.

(A)

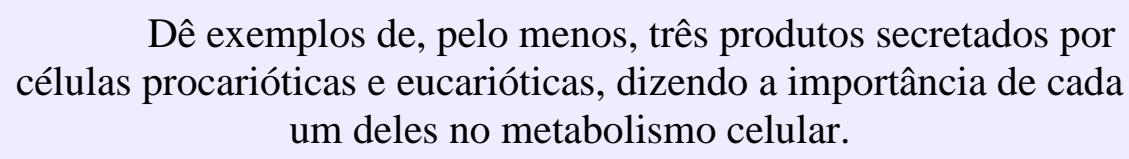

Dê exemplos de, pelo menos, três produtos secretados por células procarióticas e eucarióticas, dizendo a importância de cada um deles no metabolismo celular.

(B)

\section{Fonte: Liberto et al. (2006a, p. 58).}

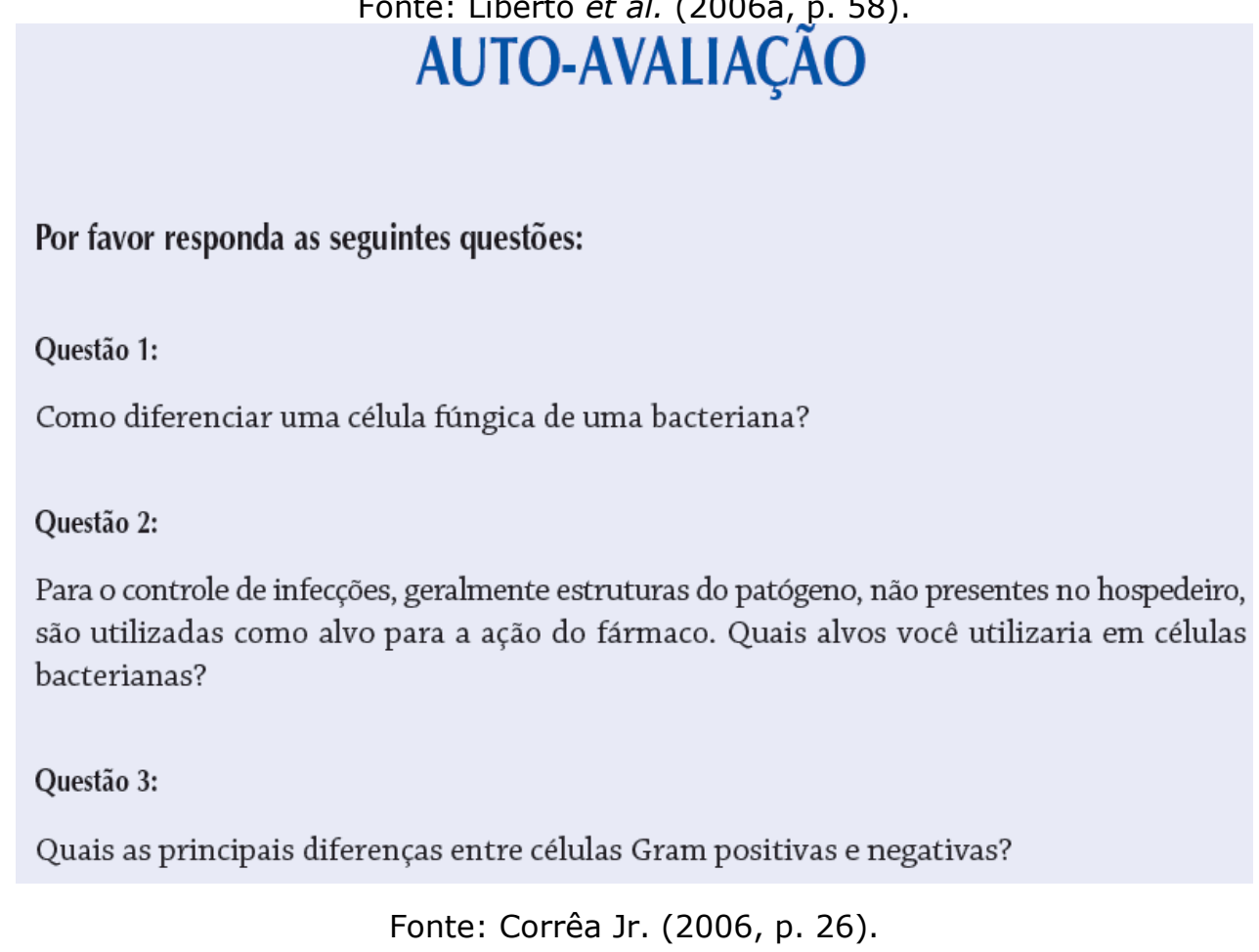

Figura 6: Exemplo de atividade formativa presente nos MDI do Cederj ( $A$ ) e da UFMG (B). 
Na resposta comentada apresentada para o questionamento da Figura 6A, é possível observar a intenção constante do autor em manter diálogo com o aluno, utilizando exemplos cotidianos a fim de facilitar o processo de aprendizagem:

\begin{abstract}
Nossas células, no processo de respiração, consomem glicose e liberam moléculas de $\mathrm{CO}_{2}$ e $\mathrm{H}_{2} \mathrm{O}$. Os seres fotossintéticos, utilizando-se de $\mathrm{CO}_{2}$ e $\mathrm{H}_{2} \mathrm{O}$ sintetizam e acumulam glicose em seus corpos. Quando estes são predados servem como fonte energética para os predadores. Você já reparou numa lágrima pendente dos olhos de alguém? Esse produto, secretado pelas glândulas lacrimais, contém enzimas, em particular a lisozima, que atua fazendo a hidrólise da mureína que compõe a parede dos micróbios, servindo como um excelente antimicrobiano, pois quando a parede bacteriana é hidrolisada a bactéria explode. E você pensava que a lágrima só servia para expressar sentimentos ou lubrificar os olhos? Se não conseguiu atingir o número de exemplos solicitado, releia o item Produtos das células, desta aula. Procedendo desta maneira, temos certeza de que você conseguirá superar essa dificuldade. Lembre-se de que esta lista pode ser bastante aumentada (Liberto et al., 2006a, p. 58).
\end{abstract}

A presença de atividades formativas em um MDI utilizado em EaD é considerada de fundamental importância para o Feedback e desenvolvimento da autonomia do aluno. Para Ribeiro \& Provenzano (1997), exercícios de autoavaliação dispostos ao final de cada módulo de estudo e acompanhados de gabarito auxiliam o aluno na avaliação de sua própria aprendizagem. As autoras ressaltam ainda que a autoavaliação é uma das partes essenciais dos cursos de EaD, o que reforça a necessidade de inserção desse tipo de atividade em MDI elaborados com essa finalidade.

\title{
4. Conclusão
}

A análise comparativa conduzida neste trabalho discutiu a importância dos desdobramentos, da conectividade, da estruturação e composição das atividades presentes em MDI para o desenvolvimento da autonomia do aluno e melhoria da eficácia do processo de ensino-aprendizagem em EaD.

Em ambos os MDI analisados, foi observada conectividade adequada, o que propicia a dinâmica ativa das aulas. No MDI do Cederj, essas conexões conduzem o aluno, em sua maioria, para um movimento para dentro do conteúdo da aula, enquanto no MDI da UFMG esse movimento ocorre predominantemente para fora da aula. No MDI do Cederj, a linearidade foi complementada pela presença de caixas de informações periféricas, que poderiam ter sido mais bem exploradas no MDI da UFMG. 
Nos dois MDI analisados foi observada a presença de inúmeras atividades, que em sua maioria estavam dispostas ao longo do texto, permitindo ao aluno verificar gradativamente sua aprendizagem antes de prosseguir a leitura. Tanto o MDI do curso oferecido pelo Cederj quanto aquele oferecido pela UFMG apresentaram predominância de atividades formativas em detrimento das demais modalidades de atividade. Isso sinaliza uma preocupação com a necessidade de fornecer um constante Feedback aos alunos, permitindo a gradativa construção do conhecimento mediante a verificação constante da aprendizagem.

Para que os MDI possam cada vez mais permitir que o estudante seja sujeito ativo da leitura e do aprendizado, é necessário que os resultados de estudos como este sejam utilizados para reformulação de bibliografias já existentes, bem como para enfatizar a importância de equipes multidisciplinares para a confecção dos materiais didáticos. Ainda considerando o constante aprimoramento dos MDI, é de extrema importância que os estudos em torno dessa ferramenta aumentem e se diversifiquem. A avaliação dos MDI deveria ser complementada por pesquisas que não só avaliem a satisfação do aluno com o material didático como também por estudos experimentais capazes de analisar como os alunos se apropriam das atividades propostas, dos elementos periféricos, ou como cada tipo de elemento pode ser utilizado por diferentes alunos.

\section{Referências bibliográficas}

ABED - Associação Brasileira de Educação a Distância. (2012). Relatório analítico da aprendizagem a distância no Brasil. Acesso em 21 maio de 2014, disponível em http://www.abed.org.br/censoead/censo2012.pdf

Abreu-Fialho, A. P. \& Barreto, C. C. (2008). Design instrucional versátil para materiais impressos contemplando diversos perfis de aprendiz e de aprendizagem. In: Congresso Internacional de EaD do Senac-Rio, 1. Rio de Janeiro. Anais... Acesso em 21 maio de 2014, disponível em http://www.nebad.uerj.br/publicacoes/artigos em anais de congressos/design instrucional \%20versatil.pdf 
Agner, L. \& Silva, F. L. C. M. (2003). Uma introdução à arquitetura da informação: conceitos e usabilidade. PUC-Rio. Acesso em 21 maio de 2014, disponível em http://www.agner.com.br/download/artigos/2CIPED Uma Introducao AI.pdf

Antunes, P. X. Q. (2011). Arquitetura da informação: Papel das informações periféricas e os recursos de desdobramento de conteúdo no material didático impresso da disciplina. Introdução à Informática do Cederj. Acesso em 21 maio de 2014, disponível em http://textolivre.com.br/artigos/36913-arquitetura-da-informacao

Araújo, F. P. et al. (2008). A incorporação da Teoria da Flexibilidade Cognitiva em ambientes virtuais de aprendizagem para incrementar a aprendizagem em sala de aula presencial. In: Simpósio Hipertexto e Tecnologias na Educação Multimodalidade e Ensino. Recife. Anais.

Barreto, C. C. (2006). Material impresso para Educação a Distância: planejamento e elaboração de um sistema instrucional. Rio de Janeiro: Fundação Cecierj/Consórcio Cederj.

Bloom, B. S., Hastings, J. T., \& Madaus, G. (1971). Handbook on formative and summative evaluation of student learning. New York: McGraw-Hill.

BRASIL. (2007). Referenciais de Qualidade para Educação Superior a Distância. Brasília: Ministério da Educação/Secretaria de Educação a Distância. Acesso em 21 maio de 2014, disponível em http://portal.mec.gov.br/index.php?option=com content\&view=article\&id $=1277$ 7\%3Areferenciais-de-qualidade-para-ead\&catid = 193\%3Aseed-educacao-adistancia\&Itemid $=865$

Campos, F. C. A., Costa, R., \& Santos, N. (2007). Fundamentos da Educação a Distância, mídias e ambientes virtuais. Juiz de Fora: Editar.

Cardoso, Z. C. S et al. (2012). Perfil dos acadêmicos do centro de Educação a Distância/Cead-Unimontes e a preferência pelo material didático impresso (mdi) quanto à disposição do texto e o entendimento da leitura. In Simpósio Internacional e Educação a Distância/Encontro de Pesquisadores em Educação a Distância. 2012. São Carlos. Anais.

Corrêa Júnior, A. (2006). Microbiologia. Belo Horizonte: Editora UFMG. 
Dutra, R. L. S., Tarouco, L. M. R., \& Passerino, L. (2008). Avaliação formativa usando objetos de aprendizagem Scorm. Novas Tecnologias na Educação, 6(1).

INED - Instituto Nacional de Educação a Distância. (2003). Conceber materiais de ensino aberto e a distância - Kit do formador 002. Acesso em 21 maio de 2014, disponível em http://www.abed.org.br/col/concebermateriais.pdf

Liberto, M. I. M., Cabral, M. C., \& Lins, U. G. C. (2006a). Microbiologia, volume 1. Rio de Janeiro: Fundação Cecierj/Consórcio Cederj.

Liberto, M. I. M., Cabral, M. C., \& Lins, U. G. C. (2006b). Microbiologia, volume 2. Rio de Janeiro: Fundação Cecierj/Consórcio Cederj.

Nunes, I. B. (2009). A história da EaD no mundo. Educação a distância: o estado da arte. São Paulo: Pearson Education.

Preti, O. (2010). Produção de material didático impresso: orientações técnicas e pedagógicas. Cuiabá: UAB/UFMT.

Ramos, R. P. C., Abreu-Fialho, A. P., \& Rabelo, C. O. (2007). Arquitetura da informação. In BARRETO, Cristine Costa (org.). Planejamento e elaboração de material didático impresso para Educação a Distância (pp. 186-209). Volume 1. Rio de Janeiro: Fundação Cecierj.

Ribeiro, A. E. \& Provenzano, M. E. (1997). Anotações sobre a produção de material impresso para a educação a distância. Tecnologia Educacional, Rio de Janeiro, ABT.

Schons, C. (2009). Validação de critérios para material didático assíncrono em Educação a Distância. Dissertação de mestrado em Engenharia e Gestão do Conhecimento. Programa de Pós-Graduação em Engenharia e Gestão do Conhecimento da Universidade Federal de Santa Catarina, Florianópolis.

Silva, C. R. O. S. (1998). Bases pedagógicas e ergonômicas para concepção e avaliação de produtos educacionais informatizados. Dissertação de mestrado em Engenharia de Produção. Programa de Pós-Graduação em Engenharia de Produção da Universidade Federal de Santa Catarina, Florianópolis.

Silva, I. M. (2010). Análise da arquitetura da informação no material didático impresso de citologia animal e vegetal do curso de Licenciatura em Ciências Biológicas a 
distância da UFMG. Monografia de especialização em Planejamento, Implementação e Gestão de EaD. Universidade Federal Fluminense, Rio de Janeiro.

Silva Filho, A. M. S. (2010). Conectividade: essencial para Educação a Distância. Revista Espaço Acadêmico, 9(104).

Vaz, F. F. \& Raposo, R. (2014). Introdução à ciência cognitiva. Acesso em 18 junho de 2014, disponível em http://www.nce.ufrj.br/ginape/publicacoes/trabalhos/t 2002/t 2002 renato ap oso e francine vaz/index.htm

Zuin, A. A. S. (2006). Educação a distância ou educação distante? O programa Universidade Aberta do Brasil, o tutor e o professor virtual. Educação \& Sociedade, 27(96). 